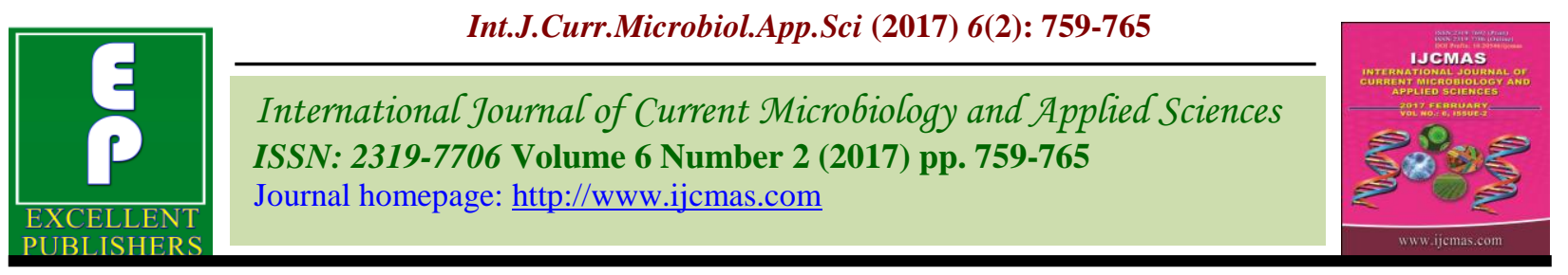

Original Research Article

http://dx.doi.org/10.20546/ijcmas.2017.602.084

\title{
Microbiological Profile of Wound Infections and their Antimicrobial Susceptibility Pattern in a Peripheral Tertiary Care Hospital of Eastern India
}

\author{
Das Munmun ${ }^{1}$ and J. Raj Hirak ${ }^{2} *$ \\ ${ }^{1}$ Department of Microbiology, Deputy Secretary, MERT, Department of Health and Family \\ Welfare, Government of West Bengal, Swasthya Bhawan, Kolkata, India \\ ${ }^{2}$ Department of Microbiology, Institute of Post-Graduate Medical Education and Research, 244 \\ AJC Bose Road, Kolkata-700020, India \\ *Corresponding author:
}

\section{A B S T R A C T}

\begin{tabular}{|c|c|}
\hline Keywords & $\begin{array}{l}\text { ceptibility pattern. A total of } 225 \text { consecutive, non-repeatıng clinical } \\
\text { arious surface wounds were collected following inclusion and exclusion }\end{array}$ \\
\hline $\begin{array}{l}\text { Surface wounds, } \\
\text { MRSA, } \\
\text { Antibiotic } \\
\text { resistance. }\end{array}$ & $\begin{array}{l}\text { criteria and processed in the Microbiology laboratory from January to June 2012, } \\
\text { following standard methodologies. A total of } 186 \text { bacterial isolates from } 142 \text { culture } \\
\text { positive samples which consisted of } 80 \text { gram-negative bacilli, } 102 \text { gram-positive } \\
\text { organisms, four atypical Mycobacteria and four Candida albicans were recovered. }\end{array}$ \\
\hline Articl & Pseudomo \\
\hline $\begin{array}{l}\text { Accepted: } \\
18 \text { January } 2017\end{array}$ & $\begin{array}{l}\text { gram positive isolates showed cent percent sensitivity to vancomycin. For gram-negative } \\
\text { bacilli, amikacin was most effective drug while } \beta \text {-lactam drugs and ciprofloxacin showed }\end{array}$ \\
\hline $\begin{array}{l}\text { Available Online: } \\
10 \text { February } 2017\end{array}$ & least sensitivity. Polymyxin B emerged as most sensitive agents against Pseudomonas \\
\hline & $\begin{array}{l}\text { rug therapy for wound infections should always be guided by the sensitivity reports for } \\
\text { ffective management of surface wound infections. }\end{array}$ \\
\hline
\end{tabular}

\section{Introduction}

Infections are common problems in surface wounds that occur as complications of trauma, surgical interventions, burn and secondary to invasive procedures. It is one of the key reasons for increased risks of patient morbidity and mortality. Bacteria seek to establish themselves in ecological niches to ensure survival and evolution. Open wounds are suitable bacteria to come and create their own niche (Stephan et al., 2008). Source of wound infections include patients' own commensal flora or organisms present in the nosocomial environment which are introduced to the patient by medical procedures or following surgery or trauma (Forbes et al., 2002). Pattern of microorganisms causing wound infection is very often subject to a combination of biological, chemical and physical factors and every single organism has its specific demand which has to be satisfied for its long term survival in any given place. Surface wounds 
seldom provide identical conditions. Hence, different wounds support different types of microorganisms to play (Cooper et al., position document). In order of frequency, Staphylococcus aureus (S. aureus) accounts for 30-50\% of skin and soft tissue infections followed by gram-negative bacteria, nonfermenters, Streptococcus pyogenes and anaerobes (Gales et al., 2000). Resistance to antimicrobial drugs is increasing everyday at an alarming rate amongst both gram-positive and gram-negative bacteria. Clinically relevant bacteria have gradually developed not only single but also multi-drug resistance - A legacy of past decades of antimicrobial usage and misuse or abuse. Development of resistance in $S$. aureus to antimicrobial agents is a major issue, starting with resistance to penicillin $G$ due to $\beta$-lactmase production followed by development of methicillin resistance in the 1960s by the mecA gene (Hartman et al., 1984). Moreover, unlike blood stream infections, surface wound infection can become polymicrobial many a times. Relevance of isolation of the bacteria/organism as offender or mere colonizer must have to be discerned to restrict antimicrobial abuse. Atypical mycobacteria have now become a well known pathogen for surface wound infections, which may not respond to empirical therapy and lead to chronicity. Continuous surveillance is therefore mandatory to monitor the bacteriological profile and antimicrobial resistance pattern to guide antibacterial therapy. This study was conducted to find out microbiological spectrum of surface wound infections and their antimicrobial susceptibility pattern in a tertiary care hospital to guide rational antimicrobial therapy.

\section{Materials and Methods}

This prospective study included consecutive 220 pus, wound swab, exudate samples obtained from various types of wounds of the patients attending Burdwan Medical College and Hospital between the months of January to June of year 2012. Samples from suspected or diagnosed cases of venous and decubitus ulcers were excluded. Two samples were obtained from each case before administration of an antibiotic or antiseptic dressing. One sample was subjected to Gram-staining and Ziehl Neelsen $(\mathrm{ZN})$ staining examination by preparation of smear for presumptive identification of likely organism/s present. Another sample was used for conventional culture. While collecting pus or exudate from abscesses, wounds or other sites, special care was taken to avoid contamination from commensal organisms of skin as far as practicable. Each sample was inoculated on 5\% Sheep blood agar, MacConky agar plates and Saboraud's Dextrose Agar slant. They were then incubated at $37^{\circ} \mathrm{C}$ for 18 to 24 hours. Suspected colonies were identified on the basis of morphological characteristics by Gram staining and by conventional biochemical tests following standard methodologies (Cruickshank et al., 1980). All the identified bacteriological pathogens were subjected to antimicrobial susceptibility testing (AST) by Kirby Bauer Disc diffusion method recommended following guideline laid down by CLSI (2012). Standard strains of E. coli ATCC 25922, S. aureus ATCC 25923 and Pseudomonas aeruginosa ATCC 27853 were used as reference strains for the standardization of AST. Detection of Methicillin resistance was carried out by standard screening procedure using $30 \mu \mathrm{g}$ Cefoxitin disc obtained from $\mathrm{Hi}$ Media Laboratory, Mumbai. Methicillin resistance for $S$. aureus was considered present when a zone of inhibition was $\leq 24 \mathrm{~mm}$, and for coagulase negative Staphylococcus when the same was found to be $\leq 23 \mathrm{~mm}$ (CLSI, 2012). Few samples showed growth of fungal yeasts in all three media used for study. The growths were further processed by Gram staining and germ tube testing (GTT) to establish their 
identity. Samples from port site infections or surgical site infections were additionally inoculated onto Lowenstein Jensen media slant (in house prepared) and incubated at $37^{\circ} \mathrm{C}$ for up to eight weeks before disposal. Any growth appearing onto the slant were processed by Ziehl Neelsen staining examination and MPT64 protein antigen detection test (MPT64 antigen detection kit obtained from commercial manufacturer) for confirmation of their identity as atypical mycobacteria. MPT64 is one of the $24 \mathrm{KDa}$ culture filtrate proteins (Yamaguchi et al., 1989) (Nagai et al., 1991) encoded by the RD2 region genes of $M$. tuberculosis complex organisms; and has been shown to be a specific antigen that differentiates the $M$. tuberculosis complex from the mycobacteria other than tuberculosis (MOTT) species (Hasegawa et al., 2002), (Abe et al., 1999). No AST was performed for the fungal yeasts and acid fast organisms isolated.

\section{Results and Discussion}

Out of 225 surface wound samples processed in this study, $142(63.11 \%)$ were culture positive and $78(34.66 \%)$ samples yielded no growth on aerobic culture. Five samples showed growth of Diphtheroids and aerobic spore bearing bacilli and they were considered contaminants, therefore not processed further. The 142 culture positive samples yielded 186 bacterial isolates out of which 108 had single pathogen and 17 had two pathogens each. Mixed growth of $S$. aureus and $E$. coli were present in nine; $S$. aureus and Acintobacter spp. in four out of these 17 samples.

Proteus vulgaris and Enterococci as mixed infections were found in four cases. Grampositive bacteria constituted 106 out of 186 and rest 80 were Gram negative bacilli. $S$. aureus $(\mathrm{n}=78 ; 41.93 \%))$ was the commonest organism present in samples; followed by $E$. coli $\quad(\mathrm{n}=22, \quad 11.82 \%), \quad$ Pseudomonas aeruginosa $(\mathrm{n}==18,9.67 \%)$ and Coagulase negative Staphylococcus $(\mathrm{n}=12, \quad 8.55 \%)$ (Table 1). Antimicrobial susceptibility and resistance pattern of bacterial isolates to various antibiotics has been shown in table 2 and table 3. All four fungal yeasts were detected as Candida albicans by GTT. Acid fast organisms were detected as and upto Atypical Mycobacteria only by MPT-64 antigen testing. AST was not performed for atypical mycobacteria and Candida spp.

Infections by multi drug resistant bacteria are a global problem. The increasing incidence and prevalence of multi-drug resistant (MDR)organisms with limited treatment options such as MDR gram-negative bacilli, methicillin resistant $S$. aureus (MRSA), Vancomycin resistant Enterococci(VRE) both in community and hospital acquired infections are matter of concern. The milieu of multi drug resistance holds true for any site of the body including wound infections. Staphylococcus aureus, E. Coli, Pseudomonas and Klebsiellae were the main pathogens detected in this study.

Comparable organism profile was also observed by Zarger et al., (2000) in their study with surgical site infections. Authors have observed a $41.93 \%$ prevalence rate of MRSA, which is almost close to what has been reported by Goyal (37.3\%) (Goyal et al., 2002); Rajaduraipandi (31.3\%) (Rajaduraipandi et al., 2006). Most strains of Staphylococcus aureus were resistant to Penicillin G (78.2\%), Ciprofloxacin (71.79\%), Erythromycin $(76.92 \%)$ in the present study (Table 2). High resistance to these drugs has also been reported by some other Indian workers (Udai Shankar et al., 1995) as well as from abroad (Bradley et al., 1985). For $S$. aureus, low resistance was observed against amikacin (29.48\%), Clindamycin (23.07\%) and levofloxacin (46.15\%). 
Table.1 Frequency of isolates from the wound samples

\begin{tabular}{|l|l|l|}
\hline Name of the isolate & $\begin{array}{l}\text { Number of isolate } \\
\text { (Total number of isolates; } \mathbf{n} \\
\mathbf{1 1 8 6})\end{array}$ & Percentage (\%) \\
\hline Staphylococcus aureus & 78 & 41.93 \\
\hline E. coli & 22 & 11.82 \\
\hline Pseudomonas aeruginosa & 18 & 9.67 \\
\hline $\begin{array}{l}\text { Coagulase negative } \\
\text { Staphylococcus }\end{array}$ & 12 & 6.45 \\
\hline Klebsiella spp & 09 & 4.83 \\
\hline Enterobacter spp. & 08 & 4.30 \\
\hline Citrobacter spp. & 07 & 3.76 \\
\hline Proteus mirabilis & 06 & 3.22 \\
\hline Proteus vulgaris & 06 & 3.22 \\
\hline Acinetobacter spp & 06 & 3.22 \\
\hline Candida albicans & 05 & 2.68 \\
\hline Enterococcus spp. & 04 & 2.15 \\
\hline Atypical Mycobacteria & 04 & 2.15 \\
\hline
\end{tabular}

Table.2 Antimicrobial resistance pattern of gram positive bacterial isolates

\begin{tabular}{|l|l|l|l|}
\hline $\begin{array}{l}\text { Antimicrobial agent } \\
\text { (in } \boldsymbol{\mu g})\end{array}$ & $\begin{array}{l}\text { Staphylococcus } \\
\text { aureus[number } \\
\text { isolate] } \\
(n=78,41.93 \%)\end{array}$ & $\begin{array}{l}\text { CoNS [number of } \\
\text { isolate] } \\
(\mathrm{n}=12,6.45 \%)\end{array}$ & $\begin{array}{l}\text { Enterococcus spp } \\
\text { [number of isolate] } \\
(\mathrm{n}=04,2.15 \%)\end{array}$ \\
\hline Penicillin G & $61(78.2 \%)$ & $7(58.33 \%)$ & $4(100 \%)$ \\
\hline Ampicillin & -- & -- & $3(75 \%)$ \\
\hline Cefoxitin & $46(58.97 \%)$ & $5(41.66 \%)$ & -- \\
\hline Ciprofloxacin & $56(71.79 \%)$ & $9(75 \%)$ & $4(100 \%)$ \\
\hline Levofloxacin & $36(46.15 \%)$ & $7(58.33 \%)$ & $3(75 \%)$ \\
\hline Gentamicin & $30(38.46 \%)$ & $4(33.33 \%)$ & -- \\
\hline $\begin{array}{l}\text { High level Gentamicin } \\
(120 m c g)\end{array}$ & -- & -- & $2(50 \%)$ \\
\hline Erythromycin & $60(76.92 \%)$ & $12(100 \%)$ & -- \\
\hline Clindamycin & $18(23.07 \%)$ & $3(25 \%)$ & -- \\
\hline Vancomycin & 00 & 00 & 00 \\
\hline Teicoplanin & 00 & 00 & 00 \\
\hline Linezolid & 00 & 00 & 00 \\
\hline Amikacin & $23(29.48 \%)$ & $2(16.66 \%)$ & -- \\
\hline
\end{tabular}


Table.3 Antimicrobial resistance pattern of gram-negaive bacterial isolates

\begin{tabular}{|c|c|c|c|c|c|c|c|c|}
\hline $\begin{array}{l}\text { Antimicrobial } \\
\text { agents }\end{array}$ & E. coli & P. aeruginosa & $\begin{array}{l}\text { Klebsiella } \\
\text { spp }\end{array}$ & Enterobacter spp. & $\begin{array}{l}\text { Citrobacter } \\
\text { spp. }\end{array}$ & P. mirabilis & P. vulgaris & $\begin{array}{l}\text { Acinetobacter } \\
\text { spp. }\end{array}$ \\
\hline (in $\mu \mathrm{g}$ ) & $\begin{array}{l}\mathrm{n}=22 \\
(\%)\end{array}$ & $\begin{array}{l}\mathrm{n}=18 \\
(\%)\end{array}$ & $\mathrm{n}=8(\%)$ & $\mathrm{n}=8(\%)$ & $\mathrm{n}=7(\%)$ & $\mathrm{n}=6(\%)$ & $\mathrm{n}=6(\%)$ & $\mathrm{n}=6(\%)$ \\
\hline Amikacin & 00 & $02(11.11)$ & 00 & 00 & 00 & 00 & 00 & $01(16.66)$ \\
\hline Gentamicin & $03(13.6)$ & $02(11.11)$ & $02(25)$ & $02(25)$ & 00 & 00 & 00 & $02(33.33)$ \\
\hline Netilmycin & $02(9.09)$ & $01(4.54)$ & $02(25)$ & $02(25)$ & 00 & 00 & 00 & $02(33.33)$ \\
\hline Cefpodoxime & $20(90.9)$ & -- & $08(100)$ & $08(100)$ & $04(57.14)$ & $04(66.66)$ & $03(50)$ & -- \\
\hline Cefotaxime & $20(90.9)$ & -- & $08(100)$ & $08(100)$ & $04(57.14)$ & $04(66.66)$ & $03(50)$ & $06(100)$ \\
\hline Ceftazidime & $20(90.9)$ & $\begin{array}{l}06 \\
(33.33)\end{array}$ & $08(100)$ & $08(100)$ & $04(57.14)$ & $04(66.66)$ & $03(50)$ & $06(100)$ \\
\hline Aztreoname & $20(90.9)$ & $03(13.63)$ & $08(100)$ & $08(100)$ & $04(57.14)$ & $04(66.66)$ & $03(50)$ & $04(66.66)$ \\
\hline $\begin{array}{l}\text { Piperacillin- } \\
\text { tazobactum }\end{array}$ & $10(45.45)$ & $05(27.77)$ & $06(75)$ & $05(62.5)$ & $03(42.85)$ & $02(33.33)$ & $01(16.66)$ & $04(66.66)$ \\
\hline Cefepime & $18(81.81)$ & $04(18.18)$ & $07(87.5)$ & $06(75)$ & $05(71.42)$ & $06(100)$ & $04(66.66)$ & $05(83.33)$ \\
\hline Imipenem & $16(72.72)$ & $8(44.44)$ & $6(75)$ & $6(75)$ & $4(57.14)$ & $4(66.66)$ & $4(66.66)$ & $4(66.66)$ \\
\hline Ciprofloxacin & $16(72.72)$ & $14(63.63)$ & $06(75)$ & $07(87.5)$ & $04(57.14)$ & $02(33.33)$ & 00 & $04(66.66)$ \\
\hline Levofloxacin & $08(36.36)$ & $14(63.63)$ & $06(75)$ & $06(75)$ & $04(57.14)$ & $01(16.66)$ & 00 & $02(33.33)$ \\
\hline $\begin{array}{l}\text { Co- } \\
\text { trimoxazole }\end{array}$ & $05(22.72)$ & -- & $03(37.5)$ & $02(25)$ & $03(42.85)$ & $03(50)$ & $02(33.33)$ & $04(66.66)$ \\
\hline Polymyxin B & -- & 00 & -- & -- & -- & -- & -- & 00 \\
\hline
\end{tabular}


A sizable section of Coagulase negative Staphylococci (CoNS) were also resistant to methicillin (41.66\%). But all S. aureus and CoNS strains were found to be $100 \%$ sensitive to vancomycin, linezolid, teicoplanin. Vancomycin is the drug of choice for treating infections caused by MRSA. However, this antibiotic should be used judiciously to prevent emergence of resistant strains among staphylococci. Isolation of Enterococci both in pure and mixed culture has been observed in four cases. Two of them were diabetic foot ulcer wounds and occurrence of Enterococci in them might be colonization. Hence those two samples were repeated twice one week apart without any invasive treatment. Both the samples yielded similar bacterial profile on culture. However, the Enterococci isolates have been found to be fully resistant to penicillin G (100\%), ciprofloxacin (100\%). A high rate of resistance has been observed by this organism towards ampicillin (75\%), levofloxacin (75\%) and High level Gentamicin (50\%). All were susceptible to vancomycin, linezolid and teicoplanin. A very high rate of antibiotic resistance was seen with Gram negative bacterial isolates (Table 3). In the cases with E. coil, Klebsiella spp, Enterobacter spp, Citrobacter spp. and Proteus spp. resistance against amikacin were comparatively lesser or minimum or even nil in some instances. So amikacin can still be used for the treatment of these infections. For Pseudomonas aeruginosa polymyxin B (zero resistance), netilmycin, amikacin and gentamicin emerged as the most sensitive drugs. They showed moderate degree of resistance towards $\beta$ lactam drugs like ceftazidime, piperacillin tazobactum. Fluoroquinolone drugs were not found to be very effective as found in the study for Pseudomonas spp. Organisms other than Pseudomonas, E.coli and Klebsiella have also shown high percentage of resistance against fluroquinolone drugs; challenging the reliability of them as empirical therapeutic options. All organisms including Acientobacter spp. showed fairly low resistance against amikacin. It was not very difficult to choose a proper antibiotic for the cases infected with Acinetobacter spp, if the options of beta-lactam, co-trimoxazole and fluroquinolone were excluded. This was a new finding as Acinetobacter spp. was notoriously known as multidrug resistant. Some variations in resistance pattern have been observed from place to place. Hence, similar study done by Shampa A has some differences in observation than ours (Shampa et al., 2006). Atypical mycobacteria were looked for in all the samples received, additionally. They were detected in four cases $(2.15 \%)$ out of total samples. All the samples were obtained from suspected SSI and PSI; and they were isolated as pure growth without any occurrence of mixed growth. Antimicrobial susceptibility pattern in the present study suggested that drug therapy for wound infections should always be guided by the sensitivity report. Infected wounds, which do not respond to treatment, should be evaluated for the presence of multi drug resistant organisms. Continuous surveillance is necessary to monitor antimicrobial resistance and antimicrobial policy should be updated according to the changing susceptibility pattern of bacteria.

\section{Acknowledgement}

Faculty and staff of Department of Microbiology, Surgery, General Medicine, Burdwan Medical College, Burdwan.

\section{References}

Abe, C., Hirano, K., Tomiyama, T. 1999. Simple and rapid identification of the Mycobacterium tuberculosis complex by immunochromatographic assay using anti-MPB64 monoclonal antibodies. $J$. Clin. Microbiol., 37: 3693-7.

Bradley, J.N., None, P. 1985. MRSA in London 
hospital. Lancet, 1: 1493-5.

Clinical and Laboratory Standards Institute. 2012. Performance standards for antimicrobial susceptibility testing; Twenty second information supplement (M100-S22). Wayne, PA: CLSI

Cooper, R.A. Understanding wound infections. Position document; University of Wales Institute, Cardiff (UK) 2-5.

Cruickshank, R., Duguid, J.P., Marmion, B.P., Swain, R.H.A. 1980. In Medical Microbiol., 12th ed. Vol.2, page 170-88.

Forbes, B.A., Sahim, D.F., Weissfeld, A.S. 2002. In Bailey and Scott's Diagnostic Microbiology; 11th ed., Mosby Inc; 9789.

Gales, A.C., Jones, R.N., Pfaller, M.A., Gordon, K.A., Sader, H.S. 2000. Two year assessment of pathogen frequency and antimicrobial resistance pattern among organisms isolated from skin and soft tissue infections in Latin American hospital: results from Sentry antimicrobial surveillance programme, 1977-98. Sentry study group. Int. J. Infect. Dis., 4: 75-84.

Goyal, R., Das, S., Mathur, M. 2002. Colonization of MRSA among health care workers in a tertiary care hospital of Delhi. Ind. J. Med. Sci., 56: 321-4.

Hasegawa, N., Miura, T., Ishii, K., Yamaguchi, K., Lindner, L.H., Merritt, S., et al. 2002. New simple and rapid test for culture confirmation of Mycobacterium tuberculosis complex: A multicenter study. J. Clin. Microbiol., 40: 908-12.

Hartman, B.J., Tomasz, A. 1984. Low affinity penicillin binding protein associated with beta-lactam resistance in Staphylococcus aureus. J. Bacteriol., 158: 513-6.

Nagai, S., Wiker, H.G., Harboe, M., Kinomoto, M. 1991. Isolation and partial characterization of major protein antigens in the culture fluid of Mycobacterium tuberculosis. Infect. Immun., 59: 372-82.

Rajaduraipandi, K., Mani, K.R., Panneerselvani, K., Mani, M., Bhaskar, M., Mankandan, P. 2006. Prevalence and antimicrobial susceptibility pattern of MRSA: A multicentre study. Ind. J. Med. Microbiol., 24: 34-38.

Shampa, A., Amitabha, B., Atul, G., Malay, R.S. 2006. Antimicrobial susceptibility of Pseudomonas aeroginosa isolated from wound infections. Ind. J. Dermatol., 51(4): 286-88.

Stephan, J., Landis, M.D. 2008. Chronic Wound Infection and Antimicrobial Use. $A d v$. skin wound care, 21: 531-40.

Udaya Shankar, C., Harish, B.N., Umesh, Kumar, P.M., Navaneeth, B.V.. 1995. Prevalence of MRSA in JIPMER hospital - A prevalence report. Ind. J. Med. Microbiol., 15: 137-8.

Yamaguchi, R., Matsuo, K., Yamazaki, A, Abe, C., Nagai, S., Terasaka, K., et al. 1989. Cloning and characterization of the gene for immunogenic protein MPB64 of Mycobacterium bovis BCG. Infect. Immun., 57: 283-8

Zarger, A.H., Msoodi, S.R., Laway, B.A., Wani, A.I., Bashir, M.I. 2000. Ciprofloxacin in the management of soft tissue infections in diabetes mellitus. $J$. Assoc. Phys. India., 48: 757-8.

\section{How to cite this article:}

Das Munmun and Raj Hirak, J. 2017. Microbiological Profile of Wound Infections and their Antimicrobial Susceptibility Pattern in a Peripheral Tertiary Care Hospital of Eastern India. Int.J.Curr.Microbiol.App.Sci. 6(2): 759-765. doi: http://dx.doi.org/10.20546/ijcmas.2017.602.084 